\title{
Contextualizações do Ensino Religioso na educação pública municipal de Juazeiro do Norte - Ceará: diálogos possiveis
}

Contextualizations of Religious Education in the municipal state education of Juazeiro do Norte (CE): possible dialogues

Rogério Paiva Castro*

Ercília Maria Braga de Olinda**

do:

https://doi.org/10.29327/256659.12.2-13

\begin{abstract}
Resumo:
O objeto desse é artigo contextualizar a realidade do Ensino Religioso no município de Juazeiro do Norte - Ceará, com vistas à percepção de aberturas para o diálogo interreligioso nas práticas pedagógicas. Subsidiados pelo Círculo Reflexivo Biográfico como dispositivo de pesquisa na vertente qualitativa, empreendemos discussões entre os líderes pedagógicos do Ensino Religioso da Secretaria Municipal de Educação e os docentes desse componente curricular. Ficou evidenciado que a abertura para o conhecimento dos fenômenos religiosos local e universal como objetivo de aprendizagem pode contribuir para que as crianças e adolescentes estejam inseridas na proposta de formação integral que vise: uma melhor compreensão da sociedade e do mundo, o reconhecimento da liberdade de expressão religiosa e não religiosa, e a promoção e a defesa da dignidade humana.
\end{abstract}

Palavras-chave: Educação; Ensino Religioso; Educação para o Diálogo.

\section{Abstract:}

The aim of this articleis to contextualize the reality of Religious Education in Juazeiro do Norte city $(\mathrm{CE})$, with a view to the perception of opening to religious dialogue in pedagogical practices. Subsidized by the Biographical Reflective Circle as a research device in the qualitative aspect,discussions between the pedagogical leaders of Religious Education fromthe Municipal Department of Education and the teachers of this curricular component have been undertaken. It has been evidenced that the opening to the knowledge of local and universal religious phenomena as a learning target can contribute to insert children and adolescents in the proposal of integral formation that aims at a better understanding of society and the world, the recognition of the freedom of religious and nonreligiousexpression, and the promotion and defense of human dignity.

Keywords: Education; Religious education; Education for Dialogue.

\footnotetext{
*Mestre em Educação pela Universidade Federal do Ceará - UFC. Professor de Língua Portuguesa e Coordenador Pedagógico na Educação Pública Municipal em Juazeiro do Norte - Ceará. Membro do Grupo de Pesquisa Dialogicidade, Formação Humana e Narrativas (DIAFHNA - CNPq/UFC). E-mail: rogeriopaivacastro@gmail.com.

** Professora aposentada da Universidade Federal do Ceará (UFC). Pesquisadora do campo das Ciências da Religião. Terapeuta holística. E-mail: erciliabragadeolinda@gmail.com
} 


\section{Introdução}

Este trabalho é decorrente de pesquisa de Mestrado Acadêmico em Educação pela Universidade Federal do Ceará (UFC), desenvolvida entre agosto de 2016 e julho de 2018, revisitada e atualizada por ocasião do V Simpósio Internacional sobre o Padre Cícero e do I Seminário de Ensino Religioso e Ciências Humanas da Secretaria Municipal de Educação de Juazeiro do Norte - Ceará, ambos realizados nesse municipio respectivamente em 2017 e 2020.

O foco da investigação foi analisar os contextos do componente curricular Ensino Religioso e suas possibilidades de abertura para o diálogo inter-religioso, sobretudo considerando o que dizem os docentes e a realidade a partir da constituição dos Planos Nacional e Municipal de Educação e da publicação da Base Nacional Comum Curricular.

O estudo foi realizado com uso de questionários padronizados e do dispositivo de pesquisa e formação denominado Círculo Reflexivo Biográfico - CRB, alternativa muito utilizada nas investigações do grupo Dialogismo, Formação Humana e Narrativas (DIAFHNA), criado em 2008 por Ercília Maria Braga de Olinda, com base nos ateliês biográficos de projetos de Christine DeloryMomberger, nos grupos reflexivos de Josso e nos Círculos de Cultura da educação popular de Paulo Freire.

$\mathrm{Na}$ primeira parte deste artigo atentamos para a realidade geral do Ensino Religioso no município, já trazendo as percepções dos professores deste componente curricular.

Em um segundo momento, observamos as relações entre o Plano Municipal de Educação de Juazeiro do Norte e a situação do Ensino Religioso local nas instituições públicas que ofertam o Ensino Fundamental.

Por fim, na terceira parte buscamos imprimir as percepções às possibilidades de um Ensino Religioso mediado por práticas dialógicas, amplamente defendidas entre as ideias de Paulo Freire e disseminadas por Morin e seus "pensamentos complexos", aportes teóricos elementares desta investigação.

\section{Realidade da educação municipal e o Ensino Religioso: o que dizem os pro- fissionais envolvidos}

É perceptível que nosso caminho vai ao encontro de um novo paradigma educacional, cujo desafio é dar liberdade ao surgimento de uma ação docente em que professores e alunos podem participar e atuar ativamente no processo de aprendizagem, que se reve- 
la dinâmico, criativo, encorajador e que tem como fundamento primordial o diálogo e as descobertas individuais e coletivas. (SME/JN - Plano Municipal de Educação de Juazeiro do Norte 2015-2025. Soeiro, 2009).

Essa proposital epígrafe visa, metalinguisticamente, dar ênfase à citação que abre o Plano Municipal de Educação da cidade em questão, cujos valores semântico-educacionais estão nas possibilidades advindas dos novos paradigmas no campo da educação, a partir dos quais as ações docentes e discentes e os processos de aprendizagem possam se fundamentar primordialmente no diálogo.

Aliás, o diálogo encontra-se previsto pelos Parâmetros Curriculares Nacionais do Ensino Religioso do Fórum Nacional Permanente do Ensino Religioso, ao destacar, no item 1.3.5, que do profissional dessa área do conhecimento se espera a disponibilidade para o diálogo e a capacidade de articulá-lo a partir de questões suscitadas no processo de aprendizagem do educando, cabendo ao docente escutar, mediar conflitos, facilitar esse diálogo e ser interlocutor na relação escola e comunidade (FONAPER/PCNERs, 2009, p. 43).

É parte da razão de ser do Ensino Religioso o conhecimento e o diálogo, cabendo à escola disponibilizar o conhecimento religioso enquanto patrimônio da humanidade, tendo esse ensino como alternativa para garantir que todos os educandos tenham a possibilidade de dialogar: "Como nenhuma teoria sozinha explica completamente o processo humano, é o diálogo entre elas que possibilita construir explicações e referenciais, que escapam do uso ideológico, doutrinal ou catequético" (FONAPER/PCNERs, 2009,p. 44-45). É o que também defende a teoria freireana e suas considerações sobre a essência do diálogo como "fenômeno humano", na ação e na reflexão, como práxis, com vistas à transformação do mundo (FREIRE, 2011, p. 107). Para o filósofo patrono da educação brasileira, “ensinar exige disponibilidade para o diálogo" (IDEM, 2015, p. 132).

Em comunhão com tais intentos estão as competências gerais da educação básica da Base Nacional Comum Curricular (BRASIL, 2017, p.10): "Exercitar a empatia, o diálogo, a resolução de conflitos e a cooperação, fazendo-se respeitar e promovendo o respeito ao outro e aos direitos humanos [...]". Assim, o acolhimento, a valorização da diversidade de indivíduos e de grupos sociais, seus saberes, identidades, culturas e potencialidades, sem preconceitos de qualquer natureza, são iniciativas que se encontram previstas para os currículos no Brasil. 
Iniciando o nosso diálogo com a realidade do Ensino Religioso, contextualizemos o espaço foco: o município de Juazeiro do Norte. Localizado na microrregião do Cariri, mesorregião Sul Cearense, a população estimada em 2020 erade 276.264 habitantes, de acordo com o Instituto Brasileiro de Geografia e Estatística - IBGE (Brasil, 2020). A cidade possui o seguinte quantitativo de instituições de ensino municipais que contemplam o Ensino Religioso, de acordo com dados coletados em atuais arquivos da Secretaria Municipal de Educação em 2021: 03 Escolas de Ensino Fundamental em Tempo Integral (EEFTI); 18 Escolas que ofertam Educação Infantil e Fundamental; e 35 que oferecem o Ensino Fundamental, totalizando 53 Escolas entre as 91 instituições municipais (Prefeitura de Juazeiro do Norte, 2021).

Para os anos finais do Ensino Fundamental ( $6^{\circ}$ ao $9^{\circ}$ ano), o último concurso público municipal (também em 2019), excepcionalmente pela primeira vez, ofertou vagas específicas para o cargo de Professor de Ensino Religioso. O Edital previa que para ocupar o cargo o concorrente poderia ter Licenciatura Plena em qualquer área das ciências humanas e curso de bacharelado em Teologia (apesar de não ser formação adequada para este fim pedagógico), Ensino Religioso ou Ciências da Religião ou Licenciatura Plena em qualquer área das ciências humanas e Pós-Graduação na área do conhecimento (Teologia, Ensino Religioso ou Ciências da Religião). Com isso, pelo menos sob o viés formal, o município se aproximou de uma contratação ideal para quem lecionaria o componente curricular em análise.

Nas escolas que ofertam os anos finais do Ensino Fundamental, cada turma tem inserida no currículo uma aula semanal de 50 (cinquenta) minutos de Ensino Religioso. Embora tenha havido concurso específico para essa área do conhecimento, pelo número de vagas para contratação imediata que contemplaria média de apenas 01 docente concursado e habilitado por escola com 40 horas semanais, é provável que ainda permaneça a prática de docentes de Geografia e História completarem carga horária com Ensino Religioso em 2021.

Nesse contexto educacional, firmamos parcerias desde o ano 2015 entre a Secretaria Municipal de Educação - SME (Coordenação Pedagógica dos Anos Finais do Ensino Fundamental e do Ensino Religioso) e o Grupo de Estudos e Pesquisas sobre Religião, Mística e Espiritualidade (GERMINAR) da Universidade Federal do Ceará, coordenado pela Professora Doutora Ercília Maria Braga de 
Olinda, autora deste artigo juntamente o outro autor Rogério Paiva Castro, orientando desta por ocasião do Mestrado em Educação concluído em 2018.

Tivemos, entre diversas situações programadas da pesquisa, um encontro com os professores de Ensino Religioso dos anos finais do Ensino Fundamental do municipio. Em um momento de formação, promovido a partir dessa parceria, a Professora Ercília Olinda desenvolveu discussões em torno do seguinte tema "O Fenômeno Religioso e Formação Humana", tendo como pautas: 1. (Re)Conhecendo o Ensino Religioso no Município; 2. Palestra Interativa com o evidenciado tema; e 3. Realização de Círculo Reflexivo Biográfico, sobre o qual falamos na introdução.

Entre outras situações de contato, esta foi uma ocasião na qual pudemos realizar discussões com os docentes de Ensino Religioso sobre a realidade do componente curricular nas salas de aula do município em questão.

Em ocasião do dia de estudo dos professores da área de Ciências Humanas nas escolas municipais, compareceram 30 docentes. Entre estes, 16 ficaram no Círculo Reflexivo que trataria do Panorama do Ensino Religioso no Município com ênfase na Formação de Professores e no Diálogo Inter-religioso, e 14 ficaram no grupo com ênfase nas relações entre o Ensino Religioso e as religiões de matrizes africanas e entre o fenômeno religioso das romarias, que culminou com outras investigações de outros membros do grupo de pesquisa. Ao longo desse artigo daremos destaque à realidade da educação e às tendências do ensino para o diálogo inter-religioso.

Neste Círculo Reflexivo Biográfico com os Professores e a Coordenadora Municipal do componente curricular em questão, realizamos discussões dirigidas, a fim de perceber, entre as demandas do Ensino Religioso, a abertura ou fechamento ao diálogo inter-religioso nas práticas pedagógicas. Os posicionamentos destes foram considerados ao longo das nossas análises na última seção.

\section{Diálogos entre o Plano Municipal de Educação de Juazeiro do Norte e o En- sino Religioso}

Em relação às supramencionadas demandas do Ensino Religioso no município de Juazeiro do Norte, atentamos para aquilo que se encontra previsto no Plano Municipal de Educação - PME-JN 2015-2025 e que se aproxima dos propósitos desse componente curricular no cumprimento do seu papel social. 
Este documento está em consonância com o Plano Nacional de Educação 2014-2024, que tem como duas de suas dez diretrizes: a "promoção humanística, científica, cultural e tecnológica do País" (Art. 2º Inciso VII) e a "promoção dos princípios do respeito aos direitos humanos, à diversidade e à sustentabilidade socioambiental" (Art. $2^{\circ}$, Inciso X).

No campo 3 - Metas e Estratégias do Plano Municipal, elege-se como uma de suas diretrizes "difundir os princípios da equidade, do respeito à diversidade e da valorização profissional e potencializar, assegurar e incentivar a gestão democrática da Educação (PME-JN, p. 56).

Como uma das estratégias para o alcance da Meta 2 - Universalizar o Ensino Fundamental de 9 (nove anos) para toda a população de 6 (seis) e 14 (catorze) anos e garantir que pelo menos $95 \%$ dos alunos concluam essa etapa na idade recomendada, até o último ano de vigência do PME: "fortalecer o monitoramento e o acompanhamento [...] das situações de discriminação, preconceitos e violências na escola, objetivando o estabelecimento de condições para o sucesso escolar do(a)s estudantes" (idem, p. 61).

Em relação à formação de professores, o Plano Municipal de Educação de Juazeiro do Norte atenta para o Previsto no PNE, que visa garantir a todo(a)s o(a)s profissionais da educação básica a formação continuada em sua área de atuação (PME-JN, p. 21), considerando também a "formação continuada de todas as áreas e modalidades de ensino" (p. 31).

Diante desses planos, dos posicionamentos dos professores e da Coordenação Pedagógica do Ensino Religioso no Município de Juazeiro do Norte, atestamos análogas realidades já percebidas em diversos escritos que reportam sobre os desafios dessa área do conhecimento no cenário brasileiro.

A aprovação da Base Nacional Comum Curricular consolida nortes para a produção de currículos das redes que articulem os conhecimentos essenciais aos quais todos os estudantes brasileiros têm o direito de ter acesso e de se apropriar durante sua passagem pela Educação Básica. É referência para o componente curricular Ensino Religioso, que historicamente esteve em constante discussão, às vezes relegado ou não reconhecido em sua essência na prática cotidiana da escola.

O debate do Ensino Religioso é, pois, iniciativa ainda premente na atual sociedade dos discursos e práticas de negação da diversidade, da subalternização 
das crenças, saberes, identidades e culturas diferentes dos modelos socioculturalmente estabelecidos, apesar dos ativismos e das políticas de ações afirmativas.

Ratificando o dito no início desse escrito, não há dúvidas de que a educação precisa se configurar permanentemente sob novos paradigmas e perspectivas diante da pluralidade cultural brasileira. Em meio à complexidade defendida pelo epistemólogo e sociólogo Edgar Morin, precisamos passar pela reforma do pensamento que considere a unidade e a multiplicidade, a articulação das explicações de ordem sociológica, econômica, jurídica, biológica, filosófica e teológica, numa superação ao paradigma simplificador das ciências clássicas e modernas. $\mathrm{Na}$ complexidade das ciências "transclássicas" pós-modernas é possível identificar a "religação" ou a "religação do que religa", numa ideia que envolve tudo aquilo que faz comunicar, associar, fraternizar, solidarizar (MORIN, 1998, passim).

Nessas vertentes de pensamento, a diversidade cultural, religiosa e dos direitos humanos e o papel ético-político da religião trazem para o Ensino Religioso o desafio daquilo que Morin denomina "religação ética", para que promova e se defenda a dignidade humana: todo olhar sobre ética deve atentar para o ato moral enquanto "ato individual de religação"; religação com o outro, religação com a comunidade, religação com a sociedade e, no limite, religação com a espécie humana (MORIN, 2011, p. 22-23).

Se estamos inseridos no tetragrama das "forças de religação e forças de separação, forças de organização e forças de desorganização, forças de integração e forças de desintegração" (MORIN, 2011, p. 35), estamos na trágica luta da religação contra a separação, a dispersão, a morte, em meio à qual podemos desenvolver o amor e a fraternidade.

Se é função do Ensino Religioso buscar a compreensão do fenômeno religioso e favorecer o diálogo entre as religiões, é a ética um de seus fundamentos epistemológicos. A expressão do imperativo de religação para os indivíduos autônomos e responsáveis - nos ditos morinianos - é também o imperativo do Ensino Religioso.

Em meio ao "policentrismo cultural e religioso" derivado das globalizações da comunicação que afetam as crenças e as religiões (COSTELLA, 2004, p. 98), quanto mais autonomia mais os individuos devem assumir a incerteza e a inquietude e mais se tem a necessidade de religação. A consciência de que todos estamos perdidos no universo deve nos conduzir à consciência de que "mais temos 
a necessidade de nos religarmos com os nossos irmãos e irmãs da humanidade" (MORIN, 2011, p. 36).

\section{Educação pública municipal: perspectivas para o diálogo inter-religioso}

A proposta pedagógica de Ensino Religioso do município de Juazeiro do Norte explicita, na exposição quanto à concepção desse ensino como componente curricular, o "pressuposto" de contribuir para a formação de pessoas, tendo como uma de suas intencionalidades a busca de qualidade de vida em sociedade.

Como contraposição à sociedade de exclusão permeada pelos preconceitos e pela alienação, propõe-se a "leitura dialética da realidade" como possibilidade de compreender os elementos contraditórios, a diversidade de relações e os elementos de unidade possiveis para a construção de uma sociedade justa, fraterna, igualitária, solidária, digna, em que o respeito ao princípio de liberdade seja considerado como busca e decisão coletiva. (Secretaria Municipal de Educação, entre 2009 e 2015, p.2).

Nessa proposta há a convicção de que a releitura do fenômeno religioso e de suas mudanças é possivel pela análise dialética das relações sociais, na busca pela compreensão dos processos sociais e culturais. Há a ideia do direito de os indivíduos professarem uma fé, "enquanto fenômeno religioso ou não, em diferentes tradições religiosas, como forma de construírem uma identidade pessoal e coletiva", prevendo também, no respeito pela vida, "o estabelecimento de uma ordem de prioridades e de organização da prática do bem comum", através da "transmissão de valores", do "desenvolvimento de atitudes, do alargamento da consciência a respeito de direitos e deveres para consigo e para com os demais" (idem, p. 3).

Amparada na Resolução 404/2005 do Conselho Estadual de Educação do Ceará $^{1}$, a proposta pedagógica do Ensino Religioso da Secretaria Municipal de Educação de Juazeiro do Norte (após 2015, até 2020, o que se apresentou como proposta de currículo foi o previsto na Base Nacional Comum Curricular) preconizava a definição dos conteúdos da programação do componente, visando: o subsídio ao aluno na compreensão do fenômeno religioso, presente nas diversas culturas e sistematizado por todas as tradições religiosas; a articulação do conhecimento religioso com os demais conhecimentos que integram a formação do cidadão; a indução ao respeito à diversidade; a promoção da prática de atitudes respeitosas em relação ao outro e à natureza; o incentivo à fraternidade e à soli- 
dariedade na convivência social; o despertar, nos alunos, do interesse pelos valores humanos; e a orientação para uma formação harmonizadora dos aspectos somáticos, emocionais e espirituais do educando.

Se para a Secretaria Municipal de Educação é relevante que "o diálogo inter-religioso seja impulsionado pelo desejo de um melhor entendimento humano, vindo a contribuir para uma melhor 'confiabilidade' [sic] humana"2; se se concebe que "a escola com a qual se sonha" deve promover o diálogo inter-religioso; se se atenta para "a tensão formada entre vivência religiosa dos docentes, a complexidade cultural e religiosa brasileira e os aspectos teórico-científicos atinentes ao estudo do fenômeno religioso e a dimensão do sagrado no cotidiano"; e se a Secretaria acredita que a efetivação dos preceitos legais do Ensino Religioso e de suas diretrizes "depende de valores interligados", como a "mudança de atitude dos profissionais da escola para que o diálogo inter-religioso seja uma realidade, o que implica, não apenas tolerar a opção do outro, mas reconhecer seu direito à livre orientação religiosa"; então percebemos que há abertura para, por exemplo, inserir a busca pelos conhecimentos atinentes ao fenômenos religiosos diversos entre os estudos dessa área do conhecimento.

Analisando a possivel abertura para o diálogo ao considerar o exemplo das romarias como fenômeno religioso, alguns professores relataram considerar tal temática em sua prática pedagógica no componente curricular Ensino Religioso, outros no componente Estudos Regionais, que é da parte diversificada do currículo municipal.

Ainda, houve quem se posicionou contrário, por considerar que, se trabalhar o referido assunto, estaria direcionando sua ação para uma "determinada religião". Elucidamos, no entanto, que tal abordagem atenderia ao objetivo da área do conhecimento em questão, por propiciar o conhecimento dos elementos básicos que compõem o fenômeno religioso percebido no contexto dos educandos, além de constituir-se apenas o estudo de um fenômeno, entre tantos outros que precisam ser abordados em sala de aula.

Em relação à prevalência do catolicismo no contexto juazeirense, houve a ideia de que esse direcionamento religioso sobrepõe a imagem do Padre Cícero (em detrimento de outras possibilidades) e que a escola e os estudantes ainda estão "relutantes" quanto à não abertura para diferentes formas de religiosidade.

A maioria, todavia, se posicionou e justificou como não sendo um empecilho para a viabilização do diálogo inter-religioso. Essas convergências e divergên- 
cias, entre aquilo que impediria ou mediaria o diálogo entre as religiões, reconfirma o paradigma da complexidade moriniano, quando lembra que cada um vive para si e para o outro de maneira dialógica, complementar e antagonicamente, associ-adoao egoísmo, mas com potencialidades fundamentais para o desenvolvimento do altruísmo (MORIN, 2011, p. 20).

Quando Morin diz que "todo olhar sobre ética deve levar em consideração que a sua exigência é vivida subjetivamente" (Id.), ele situa a fé na ética como semelhante ao aspecto místico, que parece emanar de uma "injunção sagrada". Nos tempos modernos, em que "a ética já não tem mais fundamento exterior", firma-se a fé na própria ética, cabendo não eliminar nem o componente racional nem o componente místico do universalismo ético: vale a fé na liberdade, fé na igualdade, fé na fraternidade.

Se se acredita que "a universalização da ética para todo o ser humano, seja qual for a sua identidade, só começará com as grandes religiões transculturais como budismo, cristianismo, islamismo", mesmo reconhecendo que "esse universalismo permanecerá limitado, com lacunas, frágil e será incessantemente acuado pelos fanatismos religiosos e pelos etnocentrismos nacionais", resta, em tempos de deslocamentos da relação trinária indivíduo/sociedade/espécie, o suscitar de uma ética metacomunitária em favor de todo ser humano (MORIN, 2011, p. 24).

Em tempos de crise dos fundamentos da ética e de individualismos éticos, crê-se que a área do conhecimento Ensino Religioso pode mediar a noção de que "a ética exige o pluralismo enquanto distanciamento de si mesmo e abertura ao outro" (HERMANN, 2001, p. 96) e de que "vivemos em um mundo reconhecidamente plural que traz a exigência de educar aceitando o outro em sua alteridade" (HERMANN, p. 133).

O fato de os docentes pesquisados considerarem suas práticas pedagógicas como mediadoras do diálogo inter-religioso é algo que, apesar das variáveis a se considerar nos discursos e nas próprias práticas, se torna fato alvissareiro na perspectiva de superação dos limites da relação educação e religião na comunidade una e ao mesmo tempo plural, como se houvesse indícios de valorização da diferença e vislumbres de disposição para a tolerância.

Esse posicionamento, entre os outros, parece comungar com o pensamento exposto pelo Papa Francisco na ocasião da plenária do Pontificio Conselho pa- 
ra o Diálogo Inter-religioso ${ }^{3}$, quando mencionou só existir um caminho para derrotar o medo: "é o caminho do diálogo e do encontro caracterizado pela amizade e pelo respeito". Dialogar, lembrou o pontífice "não significa renunciar a própria identi-dade, quando vamos ao encontro do outro, e não significa ceder a comprometimentos a respeito da fé e da moral cristã" (FRANCISCO, 2013, p. 138). E completa:

O futuro encontra-se na convivência respeitosa das diversidades, não na homologação a um pensamento único, teoricamente neutral. Vimos durante muito tempo na história a tragédia dos pensamentos únicos. Por isso, torna-se imprescindivel o reconhecimento do direito fundamental à liberdade religiosa, em todas as dimensões (FRANCISCO, 2013, p. 138).

A exortação de Bergoglio à Igreja de nada impor, de não recorrer a qualquer estratégia dissimulada para atrair fiéis, mas testemunhar com alegria e simplicidade "aquilo em que cremos e o que nós mesmos somos" é um convite a assumir a própria identidade e reciprocamente respeitar a identidade do outro. $\mathrm{O}$ diálogo construtivo entre pessoas de diferentes tradições religiosas, assevera o líder religioso, ajuda a também superar outro tipo de medo, que infelizmente aumenta nas sociedades que ele diz mais incisivamente secularizadas: "o receio em relação às diversas tradições religiosas e à dimensão religiosa enquanto tal" (FRANCISCO, 2013, p. 138).

Quando "as fontes da ética quase não irrigam mais", quando "a fonte individual é asfixiada pelo egocentrismo", quando "a fonte comunitária é desidratada pela degradação da solidariedade" quando "a fonte social é alterada pela compartimentação, burocratização, atomização da realidade social” e é atingida por diversos tipos de corrupção, quando "a fonte bioantropológica é enfraquecida pelo primado do indivíduo sobre a espécie” humana (Morin, 2011, p 28), é quando vemos a coerência do pensamento do Papa Francisco ainda no aludido discurso.

Esse é o tempo em que, segundo o referido pontífice,"a religião é considerada inútil, ou até perigosa" (FRANCISCO, 2013, p. 138). Como quem denuncia que em nome da demanda universalista têm-se eliminado a diferença e o particular, Bergoglio imprime sua percepção: "É comum o pensamento segundo o qual a convivência só seria possível, ocultando a própria pertença religiosa, encontrando-nos numa espécie de espaço neutro, desprovido de referências à transcendência”. (idem). 
No entanto, o líder religioso questiona: "como seria possivel criar relações autênticas, construir uma sociedade que seja verdadeira casa comum, impondo que se deixe de lado aquilo que cada um considera como uma parte intima do próprio ser?" Em resposta, afirma: "Não é possivel pensar numa fraternidade 'de laboratório". Indubitavelmente, segundo ele "é necessário que tudo se verifique no respeito das convicções do outro, até de quantos não acreditam, mas devemos ter a coragem e a paciência de irmos uns ao encontro dos outros, por aquilo que nós somos" (idem).

Em consonância com esses pensamentos, o Ensino Religioso enquanto área do conhecimento deve vir para confirmar que a religião (em seu sentido pleno, vinculada àquilo que a mantém viva, - a fonte espiritual), entre outros antigos fundamentos comunitários nacionais e étnicos que trazem "segurança psíquica e religação ética" (MORIN, 2011, p. 28) pode, sim, ser manifestada, estudada, vivida e compreendida enquanto direito humano.

A atitude pela qual o ser humano se sente ligado ao todo, como fio condutor que liga e re-liga todas as coisas, com o qual pode dialogar e entrar em comunhão com ele (a fonte originária de todas as coisas, o Mistério do Mundo ou simplesmente Deus) - Espiritualidade - e a forma de ser e de sentir que acolhe e interioriza experiencialmente esse Mistério, permitindo que ele impregne toda a existência - a Mística - são "experiências seminais que movem a vida humana e dão força aos imperativos éticos” (BOFF, 2003, p. 102), e que precisam ser consideradas na educação religiosa de proposta laica.

A despeito das diferenças doutrinais e dos múltiplos caminhos espirituais, Boff (2003, p. 105-106) lembra que as religiões convergem em alguns pontos decisivos para o "ethos mundial”, os quais são, citando Hans Küng: "o cuidado com a vida"; o "comportamento ético elementar"; a "justa medida"; a "centralidade do amor"; as "figuras éticas exemplares"; a "definição de um sentido derradeiro", o sentido do todo e do ser humano; elementos estes que trazem reservas éticas.

Assim, o Ensino Religioso em Juazeiro do Norte, que parcialmente revelou considerar as romarias como exemplo de fenômeno religioso em sua prática pedagógica, aduz ação que pode facilitar "a compreensão das formas que exprimem o Transcendente na superação da finitude humana e que determinam, subjacentemente, o processo histórico da humanidade" (FONAPER/PCNERs, p. 46), inclu- 
sive por esse caso de valorização das experiências religiosas percebidas no contexto dos educandos.

A espiritualidade, concebida por Boff (2003, p. 9) como "uma das fontes primordiais, embora não seja a única, de inspiração do novo, da esperança alvissareira, de geração de sentido pleno da capacidade de autotranscendência do ser humano" é algo vivamente perceptivel no contexto das romarias, por isso, não devendo ser assunto vilipendiado do processo no Ensino Religioso local. Como demais fenômenos religiosos de dimensão cristã, de matrizes africanas, entre outros.

A educação, que requer uma reforma programática, mas mais ainda paradigmática, precisa ir além dos saberes "desunidos, divididos, compartimentados" e das realidades "ou problemas cada vez mais multidisciplinares, transversais, multidimensionais, transnacionais, globais e planetários" (MORIN, 2000, p. 36).

\section{Considerações finais}

As formações inicial e continuada e a disposição de material didático adequado consistem em elementos indispensáveis no contexto do Ensino Religioso, todavia, é inegável que nele prepondera a necessidade da "espiritualidade", sendo esta aquilo que produz em nós uma mudança e sendo ela o possível sentido encontrado pelo próprio docente em sua predisposição à postura de abertura para melhores práticas, que contribuam para que ele mesmo e os educandos se tornem pessoas melhores.

É esse sentido que complementa e indispensavelmente pode viabilizar mudanças maiores na prática docente, que permitam que os educadores: adequadamente utilizem habilidades, métodos e técnicas pedagógicas necessários para a construção e a reconstrução do conhecimento religioso pelos educandos; reconheçam, respeitem e valorizem a diversidade e a complexidade das manifestações e experiências religiosas no contexto escolar e social, além dos princípios históricos, culturais, filosóficos, éticos, doutrinais e morais das diferentes matrizes religiosas; analisem o papel das tradições religiosas na estruturação e na manutenção das suas respectivas realidades sociais, históricas, politicas e culturais; e coletivamente busquem respostas para os seus questionamentos existen- 
ciais, no entendimento da sua(s) identidade(s) religiosa(s) ou arreligiosas e na convivência com as diferenças.

Além disso, transformações que permitam aos docentes a interpretação do fenômeno religioso na diversidade cultural local e global, com diferentes leituras, através das diversas áreas de conhecimento; o aprofundamento contínuo de seus conhecimentos; a atuação ética e comprometida, objetivando a constituição de uma sociedade justa, solidária e humana, questionando e buscando intervir nas fontes geradoras do sofrimento, da ignorância, da injustiça e da ausência de paz.

Torna-se consensual afirmar que a ética da alteridade deve ser um dos fundamentos epistemológicos e pedagógicos para a viabilização do diálogo interreligioso e intercultural, princípio basilar para o reconhecimento da diversidade cultural na perspectiva da totalidade da vida. Infelizmente ainda há situações escolares onde não se estabelece o diálogo inter-religioso. Felizmente o Ensino Religioso existe e é esperança e ocasião pedagógica oportuna para a desnaturalização das discriminações e preconceitos entre grupos humanos, orientada a seguir o caminho de reconhecimento das identidades culturais religiosas e não religiosas e ir ao encontro da convivência respeitosa e de posturas altruísticas de valorização do outro, tendo a convicção político-pedagógica paulo-freireana de que as ações dialógicas e as mudanças são atos possiveis.

\section{Referências Bibliográficas}

BOFF, Leonardo. Ethos mundial um consenso mínimo entre os humanos. Rio de Janeiro: Sextante, 2003.

BOFF, Leonardo. A convivialidade necessária para a humanidade não perecer. Jornal O Tempo - Belo Horizonte, publicado em 14/12/12 - Opinião. Disponível em http://www.otempo.com.br/opini\%C3\%A3o/leonardo-boff/a-convivialidadenecess\%C3\%A1ria-para-a-humanidade-n\%C3\%A3o-perecer-1.736. Acesso em 11 de abrilde 2021.

BRASIL. IBGE - Instituto Brasileiro de Geografia e Estatística. Ceará - Juazeiro do Norte. Disponivel em: https://cidades.ibge.gov.br/brasil/ce/juazeiro-donorte/panorama. Acesso em 10 de abril de 2021.

BRASIL. Lei $n^{\circ}$ 13.005, de 25 de Junho de 2014. Aprova: Plano Nacional de Educação - PNEe dá outras providências. Disponivel em http://www.planalto.gov.br/ccivil_03/_ato2011-2014/2014/lei/113005.htm.

Acesso em 11 de abril de 2021. 
BRASIL. Base Nacional Comum Curricular - Disponivel em http://basenacionalcomum.mec.gov.br/images/BNCC_EI_EF_110518_versaofina 1_site.pdf. Acesso em 10 de abril de 2021.

COSTELLA, Domênico. O fundamento epistemológico do Ensino Religioso. JUNQUEIRA, Sérgio; WAGNER, Raul (org.). O Ensino Religioso no Brasil. Curitiba: Champgnat, 2004.

FONAPER. Fórum Nacional Permanente do Ensino Religioso. Parâmetros Curriculares Nacionais - Ensino Religioso. $9^{\circ}$ ed. São Paulo: Mundo Mirim, 2009.

FREIRE, Paulo. Pedagogia do Oprimido. Rio de Janeiro: Paz e Terra, 2011.

FREIRE, Paulo. Pedagogia da Autonomia. São Paulo: Paz e Terra, 2015.

MORIN, Edgar. O Método 6 - Ética. Porto Alegre: Sulina, 2011.

MORIN, Edgar. A Ética do Sujeito Responsável. CARVALHO Edgar de Assis (et. al.) (org.). Ética, solidariedade e complexidade. São Paulo: Palas Athena, 1998.

MORIN, Edgar. Os sete saberes necessários à educação do futuro.Trad.de Catarina Eleonora F. da Silva e Jeanne Sawaya. $2^{\circ}$ ed. São Paulo: Cortez; Brasília: UNESCO, 2000.

PAPA FRANCISCO. Discurso do Papa Francisco aos participantes da plenária do Pontificio Conselho para o Diálogo Inter-Religioso. CNBB - Comissão Episcopal para o Ecumenismo e o Diálogo Inter-Religioso. Revista Brasileira de Diálogo Ecumênico e Inter-Religioso. Documentação,ano 02, n. 02, jan.-julho de 2014. p. 137-138.

PMJN - PREFEITURA MUNICIPAL DE JUAZEIRO DO NORTE, CEARÁ.Plano Municipal de Educação. Prefeitura Municipal. Secretaria Municipal de Educação. Conselho Municipal de Educação. Impresso. Juazeiro do Norte: PMJN, SEDUC, CME, 2015.

SME. Secretaria de Educação de Juazeiro do Norte - Ceará. Proposta Pedagógica de Ensino Religioso. Material impresso. Juazeiro do Norte, 200_.

SOEIRO, Kelma Araújo. Currículo e Formação de Professores: Construção Coletiva Dialogada. SAMPAIO, Mariza Narciso (org). Práticas de Educação de Jovens e Adultos/complexidades, Desafios e propostas. Belo horizonte: Autêntica, 2009. (Coleção estudos em EJA).

\footnotetext{
${ }^{1}$ A Resolução dispõe sobre o componente curricular Ensino Religioso a ser ministrada no ensino fundamental, nas escolas da rede pública do Sistema de Ensino do Estado do Ceará, e dá outras providências.

${ }^{2}$ A Proposta Pedagógica do Ensino Religioso da SME cita Berkenbrock (1996, p.327), embora não conste nas referências desta. "A atitude franciscana no diálogo inter-religioso"
} 
do teólogo Volney José Berkenbrock, professor do programa de pós-graduação em Ciência da Religião da Universidade Federal de Juiz de Fora - MG, encontra-se emMoreira, 1996. Onde se vê "confiabilidade" leia-se "convivialidade". Acerca deste termo, verBoff, Leonardo. A convivialidade necessária para a humanidade não perecer (consta nas referências).

3Disponível emRevista Caminhos de Diálogo - Pluralismo Religioso: Horizontes abertos. Publicação extra da Revista Brasileira de Diálogo Ecumênico e Inter-religioso da Conferência Nacional dos Bispos do Brasil). Consta nas referências como esta última.

Recebido em 08/08/2021

Aceito para publicação em 26/09/2021 